\title{
An Investigation of Knowledge Attitude and Practices Toward of Cardiovascular Disease Risk Factors Among the Patients of Metabolic Syndrome
}

\author{
Ahmet TOPTAŞ * \\ Şehit Ahmet Özsoy Devlet Hastanesi, Ankara, Turkey \\ *Corresponding author: toptasahmet06@ gmail.com
}

\begin{abstract}
Metabolic syndrome is a common global public health problem and it is characterized by a group of risk factors in one person. Metabolic syndrome (MS) is a group of cardiometabolic risk factors. Many people may not be aware of the risks for MS. MS is a condition which can lead to many complications including cardiovascular diseases (CVDs) worldwide. The aim of this study was to examine the knowledge, attitude and practices toward of cardiovascular disease risk factors in patients with Metabolic Syndrome. A total of 140 adult subjects ( 78 males and 62 females) aged 35 years and over were included in this study. The sample group consisted of patients diagnosed with metabolic syndrome from January 2018 to January 2019 who were admitted to the public hospital. Questionnaire was used to evaluate knowledge, attitude and practices toward behavior (CAP) related to CVDs disease risk factors. CAP scores were defined as poor, mean and good. Data were analyzed using descriptive statistics. ANOVA and post hoc tests were performed to determine within- and between-group differences. Level of significance was set at $\mathrm{P}<0.05$. Results: $55.8 \%$ of the participants were male, $25 \%$ were between $55-59$ years of age and $44.3 \%$ completed secondary education, $32.2 \%$ were workers and $30 \%$ were lower secondary. Participants with high application scores significantly reduced BMI and WC, suggesting that better information and practices were associated with a reduction in CVDs risk markers in these patients. Good attitude scores were associated with education and Waist circumference (WC). As a result; Despite having a good attitude, MS patients did not follow good lifestyle practices to prevent CVDs. The results of this study require intensive training interventions to prevent complications in these patients.
\end{abstract}

Keywords

Metabolic Syndrome, Cardiovascular Disease, Knowledge, Attitudes, Practices

\section{INTRODUCTION}

Metabolic syndrome is an important cause of morbidity and mortality affecting more and more people in the world and in our country (Sarti and Gallagher, 2006). Metabolic syndrome, which is known as the epidemic of the age, increases the risk of cardiovascular diseases all over the world and in our country and is considered the most important cause of death. Metabolic syndrome, also known as Insulin Resistance Syndrome, Syndrome X, Polymetabolic Syndrome or Fatal Quadruple, is the same as the increase in blood fats as a result of a defect in glucose and insulin balance in the body, excess weight, high blood pressure and glucose imbalance is an endocrinopathy that is present in many organs (Kang et al., 2002). Lifestyle changes such as regular exercise, healthy eating and weight control are recommended as first-line interventions for MS management. All of these lifestyle changes involve behavioral changes. Adequate information on the prevention and management of MS will facilitate people's adaptation to healthy behavior (Wang et al., 2019).

Metabolic syndrome (MS) represents a combination of noncommunicable diseases (NCDs) and risk factors, and the International Diabetes Federation (IDF) states that central the presence of central obesity with the following obesity: elevated triglycerides or specific treatment 
hypertriglyceridemia low HDL [high-density lipoprotein] specific treatment for cholesterol or low HDL-cholesterol, blood pressure or treatment for previously diagnosed hypertension and dysglycemia (Ford et al., 2010; Li et al., 2018). Nowadays, cardiovascular diseases (CVDs) are lethal causes in the US and industrialized countries of the world and account for about one third of the untimely death in the adult population (Karami et al., 2014). One of the ways to prevent CVDs is unhealthy lifestyle change (Imanipour et al., 2008). In developing countries, CVDs are increasing as a result of lifestyle, particularly smoking, consumption of fatty foods, lack of physical activity, and rapid changes in industrial life patterns. Unhealthy lifestyle is one of the most important factors in the development of chronic diseases such as CVDs (Mohseni et al., 2015). Physical inactivity is among the most important causes of the increase in the number of obese people. In addition, there is a close relationship between obesity and cardiovascular diseases, diabetes, osteoporosis, some types of cancer, mental problems, and many health problems in studies conducted (Demirci et al., 2018).

According to WHO and the International Diabetes Federation, treatment of MS should include lifestyle development, including balanced eating habits when they prevent regular physical activity and complications (WHO, 2009). Changing a lifestyle as an important intervention strategy may include knowledge, attitudes, social support, etc. that can determine the individual's adoption of healthy behavior. Such factors require consideration (Glanz, 1981). The literature review shows that cognitive factors (knowledge) (Murer et al., 2012) and emotional behaviors (attitude) affect healthy behaviors (Kudo et al., 2011). Positively affect healthy behavior in MS patients. The aim of this study was to examine the knowledge, attitude and cardiovascular disease risk factors in patients with Metabolic Syndrome. The findings of the study will provide valuable information to develop effective MS management strategies in this at-risk population.

\section{MATERIALS AND METHODS}

\section{Participants}

Since it was stated in the literature that 35 age and older groups were at risk for MS, this age group was included in the study. The researcher firstly screened the eligibility of patients in the study hospitals by reviewing the medical records. The study sample consisted of 140 people. After obtaining the written consent, the researcher started the data collection procedure. Patients identified as having MS when they met at least three of the five criteria: $>90 \mathrm{~cm}$ in men $>80 \mathrm{~cm}$ in women, (IDF, 2006) blood pressure (SBP> 130 $\mathrm{mmHg}$ and / or DBP> $85 \mathrm{mmHg}$ ), (Li et al., 2018) HDL - C <40 mg / dl in men and <50 mg / dl in women, (Ford et al., 2010) fasting glucose $>110$ $\mathrm{mg} / \mathrm{dl}$ or drug treatment for high glucose and (Dunbar et al., 2008) TG $\geq 150 \mathrm{mg} / \mathrm{dl}$ or drug treatment for high TG.

\section{Data Collection}

To evaluate the knowledge, attitudes and lifestyle practices of MS patients on CVD risk factors, Mirza et al. (2016) designed a questionnaire. A literature review reported the structure and content of the questionnaire. The questionnaire follows the format of the Behavioral Risk Factor Surveillance System, which was established in 1984 by the Centers for Disease Control (CDC, Atlanta, USA) and was established as a state-based health research system, gathering information on preventive health practices related to Health Risk Behaviors. The questionnaire was composed of 43 items. The information was evaluated with a series of 20 questions and the answers were recorded as correct answer (1), wrong answer or not knowing (0). Attitude was assessed with 13 questions and answers were recorded on a 0-2 Likert scale; I disagree (0), agree (1) and strongly agree (2). Lifestyle practices of the patients were evaluated with 10 questions and 0-3 - marked Likert scale, never (0), rarely do (1), sometimes do (2) and always do (3). The questionnaire was tested for internal validity and reliability. Cronbach's alpha values for "knowledge", "attitude" and "practice 0 were 0.72 , 0.8 , and 0.73 , respectively. A higher score was associated with better knowledge, positive attitudes and better practices. The scores that received maximum knowledge, attitude and practice scores as 20,26 and 30 respectively were divided into schemes classified as "poor", "average" and "good sirasiyla, respectively.

\section{Biochemistry Analysis}

After screening the patients coming to the biochemistry laboratory, data were collected from 
appropriate subjects selected by simple random sampling method. In this hospital, the laboratory of eligible for the study (meeting the eligibility criteria) departments. Patients who were found to bwere reached by a trained researcher. After obtaining informed consent, the participants were interviewed and five milliliters of 8-hour fasting venous blood samples were collected in a sterile vial under aseptic measures. Biochemical parameters (fasting blood glucose, high density lipoprotein [HDL], triglyceride [TG], glycosylated hemoglobin [HbA1C]) were analyzed.

\section{RESULTS}

The majority of the participants $(n=78$; $55.8 \%$ ) were male. Socio-demographic characteristics of the participants are given in Table 1.

Table 1. Socio-demographic Characteristics of participants

\begin{tabular}{lc}
\hline Demographic Characteristics & Frequency (\%) \\
\hline Gender & \\
\hline Female & $62(44.2)$ \\
Male & $78(55.8)$ \\
\hline Age (years) & $12(8.5)$ \\
\hline $35-39$ & $18(12.9)$ \\
$40-44$ & $23(16.5)$ \\
$45-49$ & $25(17.8)$ \\
$50-54$ & $35(25.0)$ \\
$55-59$ & $27(19.3)$ \\
60 and over & \\
\hline Education level & $8(5.7)$ \\
No schooling & $16(11.5)$ \\
Primary schooling & $62(44.3)$ \\
Secondary education completed & $42(30.0)$ \\
High school & $12(8.5)$ \\
University & \\
\hline Occupation & $27(19.3)$ \\
\hline Unemployed & $33(23.5)$ \\
Housewife & $45(32.2)$ \\
Labor-officer & $35(25.0)$ \\
Self-employment & \\
\hline Socioeconomic status & $28(20.0)$ \\
\hline Upper lower & $42(30.0)$ \\
Lower middle & $46(32.8)$ \\
Upper middle & $24(17.2)$ \\
Upper &
\end{tabular}

the biochemistry department performs blood examinations of patients referred from various $e$

\section{Statistical Analysis}

SPSS 21 version was used to derive statistical inferences. While $\mathrm{P}<0.05$ was considered significant. Data were summarized as standard deviation with ratios and means. ANOVA were used as significance tests in the analysis of qualitative and quantitative variables.

$55.8 \%$ of the individuals included in the study sample were male, $25 \%$ were between 55-59 years old and $44.3 \%$ Second Secondary education completed, 32.2\% Labor-officer, 30\% Lower Middle (Table 1).

Tables 2, 3 and 4 show the relationship between anthropometric and biochemical measurements with knowledge, attitudes and practices towards CVDs risk factors. Subjects with low BMI had better knowledge, attitudes and practices; however, it was not statistically significant. Of the studied anthropometric variables (BMI, $\mathrm{WC}$ and $\mathrm{W}$ : $\mathrm{H}$ ratio), only waist circumference was found to be significantly associated with CVDs in relation to CVDs risk factors. Lower waist circumference, knowledge, attitude and lifestyle practices were better among patients. There was a significant difference between HDL-C levels related to knowledge, attitudes and practices related to CVDs risk factors. Among the patients measured as fasting blood glucose (FBS), it was found that blood glucose control was also related to knowledge and applications of CVDs risk factors. Patients with better diabetes control (low FBS) followed good lifestyle practices and the difference was statistically significant. However, HbA1c levels and long-term control of blood glucose indicated were not significantly correlated with any of the studied variables. 
Table 2: Association of participants' anthropometric and biochemical variables with knowledge scores

\begin{tabular}{ccccc}
\multicolumn{5}{c}{ Knowledge $($ mean \pm SD* $)$} \\
\hline Variables & $\begin{array}{c}\text { Poor } \\
(\mathrm{n}=22)\end{array}$ & $\begin{array}{c}\text { Average } \\
(\mathrm{n}=76)\end{array}$ & $\begin{array}{c}\text { Good } \\
(\mathrm{n}=42)\end{array}$ & $\mathrm{p}$ \\
& $30 \pm 2.1$ & $31 \pm 2.0$ & $31 \pm 1.6$ & 0.41 \\
BMI $\left(\mathrm{kg} / \mathrm{m}^{2}\right)$ & $93 \pm 3.4$ & $90 \pm 1.2$ & $88 \pm 0.7$ & $0.01^{*}$ \\
WC $(\mathrm{cm})$ & $1.21 \pm 0.7$ & $1.26 \pm 0.6$ & $1.33 \pm 0.4$ & 0.91 \\
W:H ratio & $41 \pm 2.2$ & $43 \pm 1.5$ & $44 \pm 1.4$ & 0.07 \\
HDL-C (mg/dl) & $104.3 \pm 28$. & $105.4 \pm 30.1$ & $107.2 \pm 29.2$ & 0.23 \\
LDL-C (mg/dl) & $153 \pm 0.5$ & $149 \pm 0.7$ & $151 \pm 0.3$ & 0.51 \\
TG $(\mathrm{mg} / \mathrm{dl})$ & $130 \pm 1.3$ & $116 \pm 2.2$ & $110 \pm 1.2$ & $0.01^{*}$ \\
FBS $(\mathrm{mg} / \mathrm{dl})$ & $7.2 \pm 1.2$ & $7.4 \pm 0.3$ & $7.4 \pm 0.2$ & 0.67 \\
HbA1c $(\%)$ & & & & \\
\hline
\end{tabular}

$\mathrm{P}$ values in bold have significance $\mathrm{p}<0.05$. *SD: Standard deviation; BMI: Body mass index; WC: Waist circumference; W:H: Waist:hip ratio; HDL: High-density lipoprotein; TG: Triglyceride, FBS: Fasting blood sugar; HbA1c: Glycosylated hemoglobin

Table 3: Association of participants' anthropometric and biochemical variables with attitude scores

\begin{tabular}{ccccc}
\hline Variables & $\begin{array}{c}\text { Poor } \\
(\mathrm{n}=24)\end{array}$ & $\begin{array}{c}\text { Average } \\
(\mathrm{n}=56)\end{array}$ & $\begin{array}{c}\text { Good } \\
(\mathrm{n}=60)\end{array}$ & $\mathrm{p}$ \\
\hline BMI $\left(\mathrm{kg} / \mathrm{m}^{2}\right)$ & $31 \pm 0.5$ & $31 \pm 1.2$ & $30 \pm 2.0$ & 1.20 \\
WC $(\mathrm{cm})$ & $97 \pm 1.6$ & $92 \pm 1.6$ & $86 \pm 1.5$ & $0.01^{*}$ \\
W:H ratio & $1.4 \pm 0.3$ & $1.3 \pm 0.6$ & $1.3 \pm 0.4$ & 0.56 \\
HDL-C (mg/dl) & $40 \pm 0.4$ & $42 \pm 0.9$ & $40 \pm 0.6$ & 0.09 \\
LDL-C (mg/dl) & $106.1 \pm 28.4$ & $105.3 \pm 22.3$ & $107.6 \pm 31.8$ & 0.11 \\
TG (mg/dl) & $153 \pm 2.3$ & $151 \pm 1.4$ & $151 \pm 1.2$ & 0.41 \\
FBS (mg/dl) & $123 \pm 1.3$ & $125 \pm 2.6$ & $128 \pm 1.5$ & 0.09 \\
HbAlc $(\%)$ & $7.4 \pm 0.6$ & $7.7 \pm 1.2$ & $7.7 \pm 1.1$ & 0.54 \\
\hline
\end{tabular}

$\mathrm{P}$ values in bold have significance $<0.05 . *$ SD: Standard deviation; BMI: Body mass index; WC: Waist circumference; W:H: Waist:hip ratio; HDL: High-density lipoprotein; TG: Triglyceride, FBS: Fasting blood sugar; HbA1c: Glycosylated hemoglobin

Table 4: Association of participants' anthropometric and biochemical variables with Practice scores

\begin{tabular}{ccccc}
\multicolumn{5}{c}{ Practice $($ mean \pm SD*) } \\
\hline Variables & $\begin{array}{c}\text { Poor } \\
(\mathrm{n}=44)\end{array}$ & $\begin{array}{c}\text { Average } \\
(\mathrm{n}=62)\end{array}$ & $\begin{array}{c}\text { Good } \\
(\mathrm{n}=34)\end{array}$ & $\mathrm{p}$ \\
\hline BMI $\left(\mathrm{kg} / \mathrm{m}^{2}\right)$ & $30 \pm 1.3$ & $31 \pm 0.6$ & $28 \pm 2.1$ & 1.13 \\
WC $(\mathrm{cm})$ & $99 \pm 2.5$ & $92 \pm 1.3$ & $86 \pm 0.8$ & $0.01^{*}$ \\
W:H ratio & $1.6 \pm 0.7$ & $1.4 \pm 0.6$ & $1.2 \pm 0.3$ & 0.53 \\
HDL-C (mg/dl) & $39 \pm 1.6$ & $42 \pm 0.7$ & $40 \pm 1.5$ & 0.06 \\
LDL-C (mg/dl) & $107.1 \pm 34.6$ & $106.4 \pm 31.4$ & $102.5 \pm 31.8$ & 0.32 \\
TG $(\mathrm{mg} / \mathrm{dl})$ & $153 \pm 2.0$ & $151 \pm 1.1$ & $150 \pm 1.0$ & 0.20 \\
FBS $(\mathrm{mg} / \mathrm{dl})$ & $132 \pm 0.8$ & $122 \pm 1.3$ & $108 \pm 2.3$ & $0.01^{*}$ \\
HbA1c $(\%)$ & $7.8 \pm 1.0$ & $7.4 \pm 0.3$ & $7.5 \pm 0.6$ & 0.71 \\
\hline
\end{tabular}

$\mathrm{P}$ values in bold have significance <0.05. *SD: Standard deviation; BMI: Body mass index; WC: Waist circumference; W:H: Waist:hip ratio; HDL: High-density lipoprotein; TG: Triglyceride, FBS: Fasting blood sugar; HbA1c: Glycosylated hemoglobin 


\section{DISCUSSION AND CONCLUSION}

Metabolic syndrome is a modern life disease. MS is considered an epidemic of the 2000s. Metabolic syndrome prevalence was found to be different in different populations (Yang et al. 2002). The prevalence of metabolic syndrome in adults is reported to be $23 \%$ in the United States (USA), between $12 \%$ and $28 \%$ in European countries, and in the UK, $25 \%$ of the population is diagnosed with definite metabolic syndrome (Ford et al., 2002).

Our findings suggest that patients with MS have a moderate level of knowledge and practice and a high level of attitudes towards reducing CVDs risk, but that knowledge and practice are low in some areas. Active lifestyles contribute to the maintenance and improvement of health and wellbeing and prevention of disease among people (American College of Sports Medicine, 2009). In particular, physical activity (PA) reduces the risk of cardiovascular disease (Demirci et al., 2018).

An important aspect of our study was that participants with high knowledge scores significantly reduced WCs and tended towards lower FBG levels. Similarly, participants with high application scores significantly reduced BMIs and WCs, making it clear that better information and practices are associated with better anthropometric and biochemical parameters to reduce the risk of CVDs in these patients (Simpson et al., 2004) Overall, the information was average among most patients. It was associated with sociodemographic, anthropometric and biochemical measurements. The fact that the literacy rates among the participants were low and that they caused their awareness to decrease were not well educated. The waist circumference was lower and the sugar control was better, so the information was better in patients with low FBS levels. In a study, Amarasekara et al. (2016) reported that patients with low waist circumference and low FBS had a higher knowledge score about CVDs risk factors.

It was significantly correlated with MS knowledge in previously published studies. In addition, participants with a history of dyslipidemia or a high level of normal HDL-C had more MS knowledge (Wang et al., 2015). These participants may have received training in MS after the diagnosis of dyslipidemia. In addition, when participants are aware of the diagnosis of dyslipidemia, they can pay attention to selflearning of relevant information. People with normal HDL-C levels knew more about MS, which indicates the positive impact of information on disease management (Lo et al., 2015; Zhao and Zhang, 2008). Compared to other studies on CVDs and risk factors, this population also demonstrated broad discrepancies in knowledge, as well as inconsistency between knowledge and attitudes. However, it is not easy to make sustainable changes to lifestyle practices. Various studies on NCDs have shown that there are many interrelated problems associated with individual behavior, so that even if knowledge and attitudes are high, implementation remains low (Parvin et al., 2010; Oguoma et al., 2014).

\section{Conclusion}

The results support the need for a health promotion strategy among MS patients. Because of the significant differences between the various socio-demographic groups, health promotion interventions should be planned and implemented with different studies. The results also show the health department's difficulties in persuading patients to change their lifestyle, which is only possible through intensive counseling sessions and health promotion policies. In view of all these aspects, in addition to diagnosing MS, there is a need to identify individuals at risk for CVDs to identify and treat additional risk factors in patients with only one or two risk factors. Future planning programs are well targeted and more directive to focus more on the behavioral aspects of managing information and risk reduction. The aim of prevention / reduction of CVDs risk is to investigate further the barriers and chambers of increasing patient knowledge and practices.

\section{REFERENCES}

Amarasekara P, de Silva A, Swarnamali H, Senarath U, Katulanda P (2016). Knowledge, attitudes, and practices on lifestyle and cardiovascular risk factors among metabolic syndrome patients in an Urban Tertiary Care Institute in Sri Lanka. Asia Pac J Public Health;28(1 Suppl):32S-40S.

Demirci N, Toptaş Demirci P, Demirci E (2018). The Effects of Eating Habits, Physical Activity, Nutrition Knowledge and Selfefficacy Levels on Obesity. Universal 
Journal of Educational Research 6(7): 14241430

Demirci N, Yıldırım İ, Toptaş Demirci P, Ersöz Y (2018). Why Should We Do Physical Activity? More Active People For A Healthier World. Int J Disabil Sports Health Sci;1(2);1-14

Dunbar J.A, Reddy P, Davis-Lameloise N, Philpot B, Laatikainen T, Kilkkinen A, Bunker S.J, Best J.D, Vartiainen E, Kai Lo S (2008). Depression: An important comorbidity with metabolic syndrome in a general population. Diabetes Care, 31, 2368-2373.

Ford E.S, Li C, Zhao G(2010). Prevalence and correlates of metabolic syndrome based on a harmonious definition among adults in the US. Diabetes Care, 2, 180-193.

Ford E.S, Giles W.H, Dietz W.H (2002). Prevalence of the metabolic syndrome among US adults. Findings from the third National Health and Nutrition Examination Survey. JAMA, 287: 356-359.

Glanz K, Kirscht JP, Rosenstock IM (1981). Linking research and practice in patient education for hypertension: Patient responses to four educational interventions. Med Care; 19:141-52.

Imanipour M, Bassampour S, Haghani H (2008). Relationship between preventive behaviors and knowledge regarding cardiovascular diseases. Hayat;14(2):41-9.

International Diabetes Federation (2006). The IDF Consensus Worldwide Definition of the Metabolic Syndrome; International Diabetes Federation: Belgium; Available online: https://www.idf.org/component/

attachments/attachments.html?id=705\&task= download (accessed on 14 june 2019).

Kang HS, Gutin B, Barbeau P, Litaker MS, Allison J, Le NA (2002). Low-density lipoprotein particle size, central obesity, cardiovascular fitness, and insulin resistance syndrome markers in obese youths. Int $\mathbf{J}$ Obes Relat Metab Disord., 26: 1030-1035.

Karami J, Komasi S, Maesoomi M, Saeedi M (2014). Comparing the effectiveness of two methods of relaxation and interpersonal cognitive problem solving on decreasing anxiety and depression in cardiac rehabilitation patients. Urmia Med $\mathrm{J} ; 25(4): 298-308$.
Kudo Y, Okada M, Tsunoda M, Satoh T, Aizawa Y.A (2011). Lifestyle to prevent or combat the metabolic syndrome among Japanese workers: Analyses using the health belief model and the multidimensional health locus of control. Ind Health;49:365-73.

Li Y, Zhao L, Yu D, Wang Z, Ding G (2018). Metabolic syndrome prevalence and its risk factors among adults in China: A nationally representative cross-sectional study. PLoS ONE, 13, e0199293.

Lo S.W.Z, Chair S.Y, Lee I.F.K (2015). Knowledge of metabolic syndrome in Chinese adults: Implications for health education. Health Educ. J., 75, 589-599.

Mirza A, Aslam S, Perin K, Curtis T, Stenback J, Gipson J, Alrabaa S (2016). Knowledge, attitudes and practices among patients with coronary artery disease in Dhaka, Bangladesh. Int J Community Med Public Health; 3:2740-8.

Mohseni Pouya H, Hajimiri K, Esmaeili Shahmirzadi S, Golshani S, Hashemi Amrei S, Eifi Makrani A (2015). Relationship between health promoting behaviors and severity of coronary artery stenosis in angiography department in Mazandaran Heart Center]. Mazandaran Med J.; 25(130):19-29.

Murer M, Schmied C, Battegay E, Keller DI (2012). Physical activity behaviour in patients with metabolic syndrome. Swiss Med Wkly;142:w13691.

Oguoma VM, Nwose EU, Bwititi PT (2014).Cardiovascular disease risk prevention: preliminary survey of baseline knowledge, attitude and practices of a Nigerian rural community. $\mathrm{N}$ Am J Med Sci;6: 466-471.

Parvin M, Fatemah MN, Nasrin O, et al. (2010). Nutritional knowledge, attitude and practice of Teheranian adults and their relation to serum lipids and lipoproteins: Teharan lipid and glucose study. Ann Nutr Metab;56:233240.

Sarti C, Gallagher J (2006). Metabolik sendrom Prevalansı, KKH riski ve tedavisi. J Diabet. Comp.2: 106-120. 
Simpson DR, Dixon BG, Bolli P (2004). Effectiveness of multidisciplinary patient counselling in reducing cardiovascular disease risk factors through nonpharmacological intervention, Ontario. Can J Cardiol; 20:177-186.

Wang Q, Chair SY, Mi-Ling Wong E, TaylorPiliae RE, Hui Qiu XC and Mei Li X (2019). Metabolic Syndrome Knowledge among Adults with Cardiometabolic Risk Factors: A Cross-Sectional Study, Int. J. Environ. Res. Public Health, 16, 159;1-10.

Wang J.H, Dong L.P, Jiang H.J (2015). The survey of clinical nurses' understanding on metabolic syndrome. Chin. Rural Health Serv. Adm, 35, 253-255.
World Health Organization (2009). The metabolic syndrome. In: Department of Noncommunicable Disease Surveillance, editor. Definition, Diagnosis and Classification of Diabetes Mellitus and its Complications. Report of a WHO Consultation. Geneva: World Health Organization; 1999. p. 31-3. Available from: http://apps.who.int/iris/bitstream/10665/6604 0/1/WHO_NCD_NCS_99.2.pdf.(Last accessed on 2019 june 14).

Yang WS, Lee WJ, Funahashi T, Tanaka S, Matsuzawa Y, Chao CL, Chen CL, Tai TY, Chuang LM. (2002). Plasma adiponectin levels in overweight and obese Asians. Obes Rev., 10: 1104-1110.

Zhao X.J, Zhang S.M.A (2008). survey of knowledge about metabolic syndrome in medical workers. Neural Injury Funct. Reconstruct, 3, 173-175. 